\title{
Identification of hub genes involved in the occurrence and development of hepatocellular carcinoma via bioinformatics analysis
}

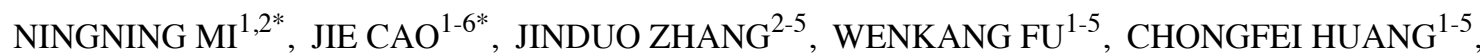

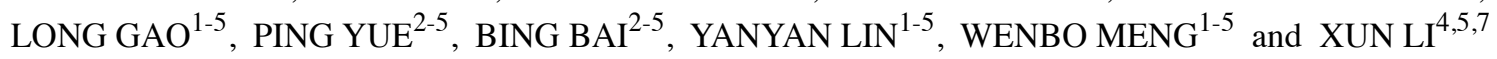 \\ ${ }^{1}$ The First Clinical Medical School, Lanzhou University; ${ }^{2}$ Department of Special Minimally Invasive Surgery, \\ The First Hospital of Lanzhou University; ${ }^{3}$ Institute of Genetics, School of Basic Medical Sciences, Lanzhou University; \\ ${ }^{4}$ Gansu Province Institute of Hepatopancreatobiliary; ${ }^{5}$ Gansu Province Key Laboratory Biotherapy and \\ Regenerative Medicine; ${ }^{6}$ Laboratory Department; ${ }^{7}$ The Fifth Department of General Surgery, \\ The First Hospital of Lanzhou University, Lanzhou, Gansu 730000, P.R. China
}

Received September 28, 2019; Accepted May 7, 2020

DOI: $10.3892 / \mathrm{ol} .2020 .11752$

\begin{abstract}
Hepatocellular carcinoma (HCC) is a heterogeneous malignancy, which is a major cause of cancer morbidity and mortality worldwide. Thus, the aim of the present study was to identify the hub genes and underlying pathways of HCC via bioinformatics analyses. The present study screened three datasets, including GSE112790, GSE84402 and GSE74656 from the Gene Expression Omnibus (GEO) database, and downloaded the RNA-sequencing of HCC from The Cancer Genome Atlas (TCGA) database. The differentially expressed genes (DEGs) in both the GEO and TCGA datasets were filtered, and the screened DEGs were subsequently analyzed for functional enrichment pathways. A protein-protein interaction (PPI) network was constructed, and hub genes were further screened to create the Kaplan-Meier curve using cBioPortal. The expression levels of hub genes were then validated in different datasets using the Oncomine database. In addition, associations between expression and tumor grade, hepatitis virus infection status, satellites and vascular invasion were assessed. A total of 126 DEGs were identified, containing 70 upregulated genes and 56 downregulated genes from the GEO and TCGA databases. By constructing the PPI network, the present study identified hub genes, including
\end{abstract}

Correspondence to: Dr Yanyan Lin or Professor Wenbo Meng, Department of Special Minimally Invasive Surgery, The First Hospital of Lanzhou University, 1 Donggang West Road, Lanzhou, Gansu 730000, P.R. China

E-mail: ldyy_linyy@lzu.edu.cn

E-mail: mengwb@1zu.edu.cn

*Contributed equally

Key words: hepatocellular carcinoma, hub genes, prognosis, bioinformatics, microarray cyclin B1 (CCNB1), cell-division cycle protein 20 (CDC20), cyclin-dependent kinase 1, BUB1 mitotic checkpoint serine/ threonine kinase $\beta$ (BUB1B), cyclin A2, nucleolar and spindle associated protein 1, ubiquitin-conjugating enzyme E2 C (UBE2C) and ZW10 interactor. Furthermore, upregulated CCNB1, CDC20, BUB1B and UBE2C expression levels indicated worse disease-free and overall survival. Moreover, a meta-analysis of tumor and healthy tissues in the Oncomine database demonstrated that BUB1B and UBE2C were highly expressed in HCC. The present study also analyzed the data of HCC in TCGA database using univariate and multivariate Cox analyses, and demonstrated that BUB1B and UBE2C may be used as independent prognostic factors. In conclusion, the present study identified several genes and the signaling pathways that were associated with tumorigenesis using bioinformatics analyses, which could be potential targets for the diagnosis and treatment of HCC.

\section{Introduction}

Hepatocellular carcinoma (HCC) is one of the few cancer types associated with a rising incidence in recent years, with the incidence in Mongolia being as high as 93.7 per 100,000 individuals (1). Certain aspects of the etiology and development of HCC have been reported, and it is speculated that the complex pathogenesis of HCC is associated with cirrhosis, viral hepatitis, aflatoxins, specific chemical carcinogens and abnormal regulation of hormones (2,3). Among these, chronic liver disease is the most important factor leading to the occurrence of liver cancer (4). The infection of hepatitis $\mathrm{B}$ virus (HBV) accounts for $60 \%$ of $\mathrm{HCC}$ cases in developing countries and for $23 \%$ of cases in developed countries, while infection of hepatitis $\mathrm{C}$ virus (HCV) accounts for $23 \%$ of $\mathrm{HCC}$ cases in developing countries and $20 \%$ of cases in developed countries (5). Moreover, sub-Saharan Africa, East Asia and Southeast Asia are the regions with the highest incidence of $\mathrm{HBV}$, while USA, Europe and Japan have high incidences of $\mathrm{HCV}$ (4). The incidence of non-alcoholic fatty liver disease 
(NAFLD) is increasing with the rise in obesity and other metabolic syndromes, which seriously affects the health of the affected individual (6). According to data generated from a cross-sectional study, 25-30\% of people with a Western lifestyle have a fat content in their liver that exceeds the normal level; of these, $2-5 \%$ suffer from NAFLD, and 1-2\% of the affected adults may be at risk of developing non-alcoholic steatohepatitis cirrhosis (7).

The incidence of HCC is increasing worldwide; however, early diagnoses and treatment of HCC remain an issue (4). Due to the low-level medical and healthcare in developing countries, the incidence of $\mathrm{HCC}$ is rising, with an estimated global incidence of liver cancer per 100,000 individuals being 9.3 in 2018 (1), and the prognosis is poor (8). For patients without liver cirrhosis and distant metastasis of the tumor, hepatic resection is currently the first treatment choice and the most effective way to treat HCC (4). However, for patients with liver cirrhosis, surgical resection is a contraindication, and liver transplantation should be performed to achieve a favorable prognosis (4). The size of the tumor is not the definite limiting factor for surgery; the presence or absence of distant metastasis and vascular invasion are the main factors considered for surgical resection (9). In recent years, laparoscopic hepatectomy has become a major surgical method of radical resection of tumors (10). Furthermore, compared with traditional open surgery, laparoscopic surgery is minimally invasive, which has the advantages of small trauma, fewer perioperative complications and quick postoperative recovery, while having a similar prognosis to open surgery (10). For patients without indications for surgical resection, minimally invasive treatment can be applied according to a variety of factors such as tumor characteristics, complications, tumor site and performance status (4). Local treatment methods include radiofrequency ablation and microwave ablation, while other therapeutic methods are locoregional therapies such as chemoembolization and radioembolization (11). Moreover, systemic chemotherapy is a feasible method to improve the survival rate of patients with advanced liver cancer $(3,4)$. Sorafenib is a first-line drug for the treatment of advanced HCC (12). With the development of sorafenib derivatives, additional satisfactory antitumor drugs are expected to be developed (12). In addition, gene chip technology for the study of liver cancer can accurately depict the molecular expression profile of HCC and identify the specific genes associated with HCC (13-15).

Microarray technology, which is a highly efficient and accurate transcriptional expression technology, has been successfully applied in the screening of molecular markers of almost all human malignant tumors, particularly liver cancer. The present study obtained GSE112790, GSE84402 and GSE74656 microarray datasets from the Gene Expression Omnibus (GEO) database. In addition, RNA-sequence (seq) data were downloaded from The Cancer Genome Atlas (TCGA) database and further analyzed via bioinformatics methods. These analyses resulted in the identification of a series of hub genes that may be associated with HCC, which might be used as molecular markers in the early diagnosis and treatment targets of HCC.

\section{Materials and methods}

Data source. The present study downloaded three datasets, namely GSE112790 (16), GSE84402 (17) and
GSE74656 (https://www.ncbi.nlm.nih.gov/geo/query/acc. cgi?acc=GSE74656), from the GEO database (http://www. ncbi.nlm.nih.gov/geo/), and the following conditions were met for each set of samples: i) Samples were obtained from human liver tissue; ii) chips contain both healthy samples and tumor tissue of HCC; iii) the total number of samples $\geq 10$.

GSE112790 and GSE84402 datasets were based on GPL570 (Affymetrix Human Genome U133 Plus 2.0 Array; Affymetrix; Thermo Fisher Scientific, Inc.; http://www. affymetrix.com/index.affx), while GSE74656 was based on GPL16043 (GeneChip ${ }^{\circledR}$ PrimeView $^{\mathrm{TM}}$ Human Gene Expression Array with external spike-in RNAs; Affymetrix; Thermo Fisher Scientific, Inc.; http:/www.affymetrix.com/ index.affx). The GSE112790 dataset contained 15 healthy liver tissues and 183 tumor samples, while the GSE84402 dataset contained 14 healthy liver samples and 14 malignant tissues. Moreover, the GSE74656 dataset contained five healthy liver and five malignant liver tissues. The RNA-seq of HCC consists of 374 tumor liver samples and 50 healthy tissues that were downloaded from TCGA database (https://cancergenome.nih. gov/).

Screening for differentially expressed genes (DEGs). The raw data of the gene expression profiles were analyzed using R software v3.5.2 (https://www.r-project.org) and the Bioconductor package 'Limma' v3.36.5 (https://bioconductor.org/packages/ limma/) (18). The robust multi-array average method (19) was used to complete background correction and normalization of all original microarray data. Subsequently, the present study used the combat function of the 'sva' package v3.30.1 (https:// bioconductor.org/packages/sva/) (20) of R to remove any batch effect. DEGs were screened using the 'Limma' package, and the Bioconductor package 'edgeR' v3.24.3 (21) was used to analyze and process the data downloaded from TCGA database. The screening criteria for DEGs were both adjusted to $\mathrm{P}<0.01$ and llog fold-changel $>2.0$.

Functional enrichment analysis of DEGs. In order to perform Kyoto Encyclopedia of Genes and Genomes (KEGG; https:// www.kegg.jp) pathway and Gene Ontology (GO; http:// geneontology.org) function analyses, DEGs were submitted to the Database for Annotation, Visualization and Integrated Discovery (DAVID; https://david.ncifcrf.gov/). Biological annotations were considered to be significantly enriched when $\mathrm{P}<0$.05. DAVID bioinformatics resources include an integrated biological knowledge base and analytical tools designed to systematically extract biological significance from large gene lists (22). The results were visualized using the GOChord and GOCircle functions of 'GOplot' package v1.0.2 (https:// CRAN.R-project.org/package=GOplot) (23).

Construction of protein-protein interaction (PPI) network and analysis of modules. The Search Tool for the Retrieval of Interacting Genes (STRING; https://string-db.org/) online software (24) and Cytoscape tools were utilized to construct a PPI regulatory network of DEGs. Cytoscape 3.6.0 (https:// cytoscape.org/) is a free software that graphically displays PPI networks, and performs analysis and editing. Moreover, Cytoscape is an application that runs on a personal computer rather than on a web browser (25). Medium confidence (0.400) 


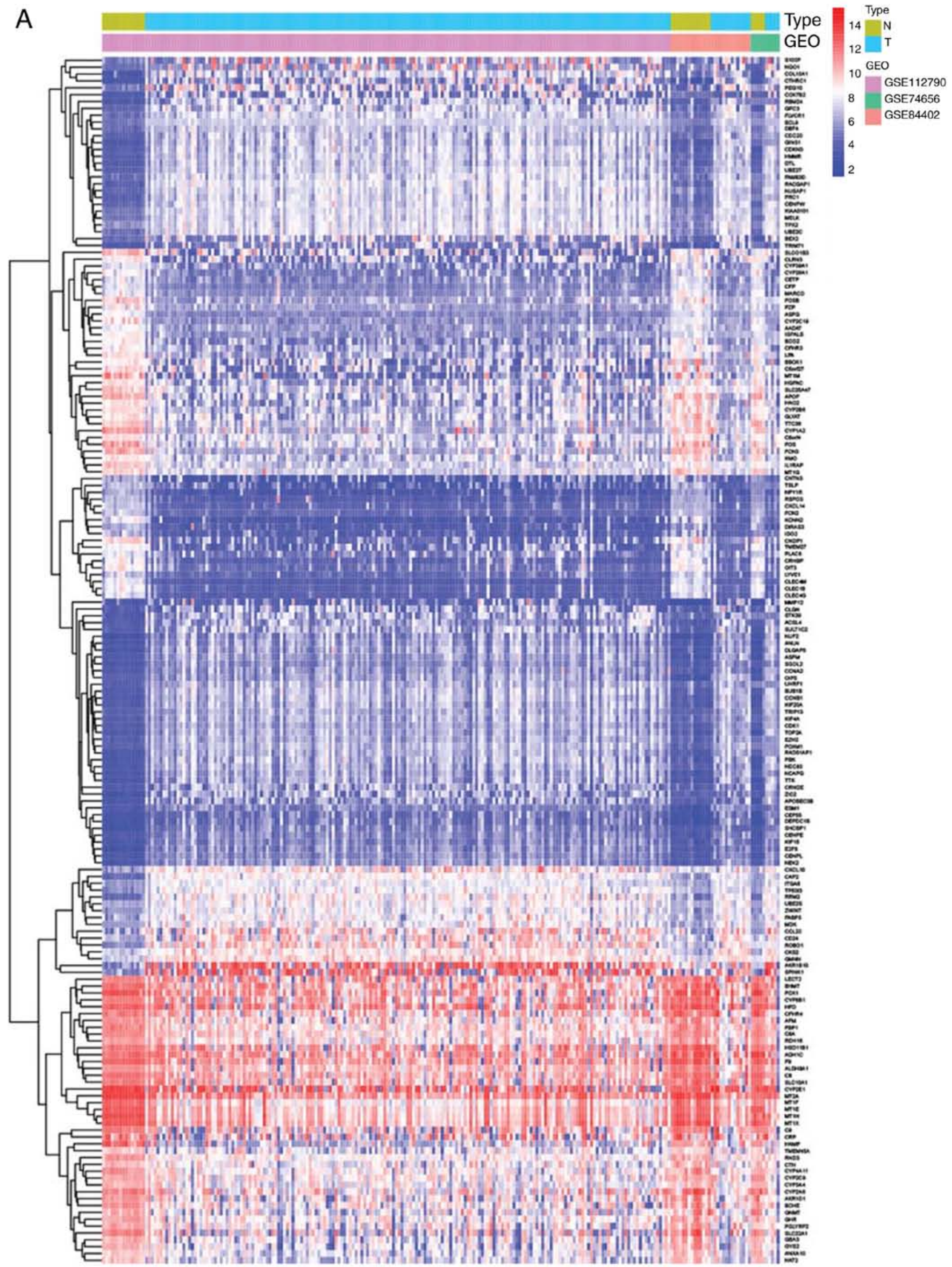


B

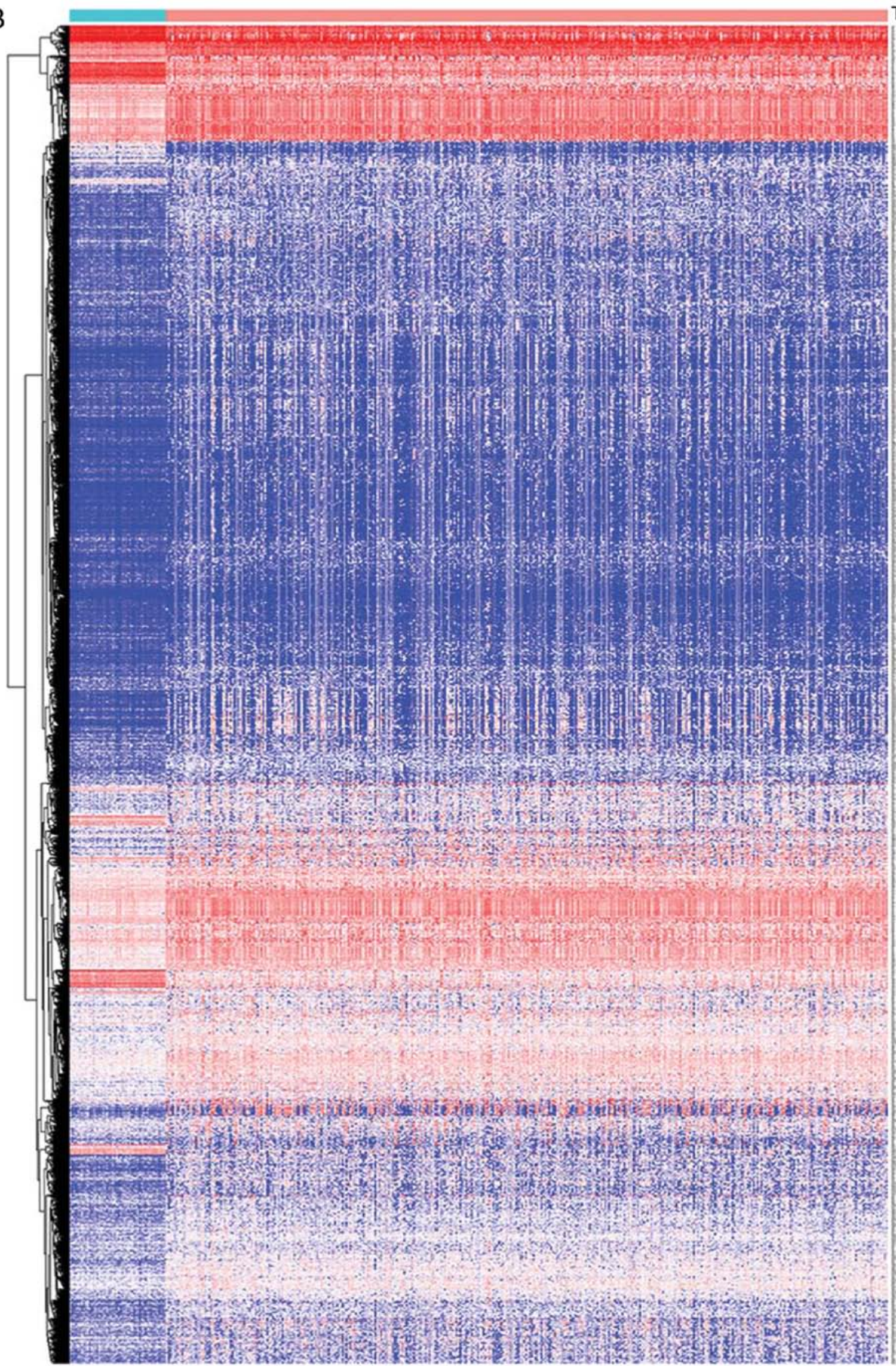

Type

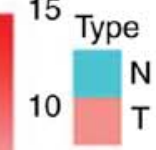

5

0

$-5$

Figure 1. Continued. (B) Heat map of TCGA datasets. Red lines represent upregulation and blue lines represent downregulation. DEGs, differentially expressed genes; GEO, Gene Expression Omnibus; TCGA, The Cancer Genome Atlas; N, normal tissues; T, tumor tissues. 
was implied in the STRING tool. The present study utilized the plug-in Molecular Complex Detection (MCODE 1.5.1) (26), an application of Cytoscape, to mine the core modules of PPI networks that were significantly associated with liver cancer, and further investigate the biological functions of the module. The criteria for screening are as follows: Degree cut-off $=2$; node score cut-off $=0.2$; maximum depth $=100$; and $\mathrm{k}$-score $=2$. Hub proteins were selected based on their associations with other proteins, which were sorted by the degree value in the network.

Selection and analysis of hub genes. The numbers of nodes and edges in the PPI network were counted in order to screen for hub genes. The present study used the Kaplan-Meier curve to determinate the overall and disease-free survival of the hub genes in the Liver Hepatocellular Carcinoma (TCGA, Firehose Legacy; https://www.cbioportal.org/study/summary?id=lihc_ tcga) database of the cBioPortal for cancer genomics (v3.0.2; http://www.cbioportal.org/) (27,28). The study downloaded the original data of hub genes and used the Renyi test to determine if there is a significant difference in survival rate between two groups when their survival curves cross each other using SAS software v9.4 (SAS Institute, Inc.) (29).

For the purpose of assessing the expression levels of hub genes in different datasets, these were submitted to the Oncomine (https://www.oncomine.org/) database (30), which was also used to analyze the association between gene expression and tumor grade, hepatitis virus infection status, satellites and vascular invasion by analyzing the Wurmbach Liver dataset (31). The clinical data of HCC from TCGA database was then obtained, and the 'survival' package (v3.1-8; https:// CRAN.R-project.org/package=survival) of $\mathrm{R}$ software was used to perform a univariate analysis and construct the multivariable Cox regression models on BUB1B and UBE2C, and other clinicopathological parameters, and calculated hazard ratios and corresponding $95 \%$ confidence intervals.

Gene set enrichment analysis (GSEA). In order to investigate the biological functions and pathways of different expression levels of core genes, GSEA was performed using GSEA software (v4.0.2; http://software.broadinstitute.org/gsea/ index.jsp) (32) with gene set c2 (cp.kegg.v7.0.symbols.gmt) from the Molecular Signatures Database (MSigDB; https:// www.gsea-msigdb.org/gsea/msigdb). The MSigDB of $\mathrm{c} 2$ is a pathway gene set, which was curated from published canonical pathways and experimental signatures (33). $\mathrm{P}<0.05$ and false discovery rate $($ FDR $)<0.25$ were considered to indicate a statistically significant difference.

\section{Results}

Screening for DEGs. In total, 126 genes that met the differential threshold were screened by bioinformatics methods. Overall, 83 genes were upregulated and 93 genes were downregulated in the GEO datasets, which contained a total of 34 healthy samples and 202 cancer samples. In total, 374 tumors and 50 healthy liver tissues were analyzed in TCGA database using the same bioinformatics methods, and 3,297 upregulated and 300 downregulated genes were identified. Hub genes were identified according to the adjusted $\mathrm{P}<0.01$ and a $\log$ fold-changel of $>2.0$.
The heatmaps and volcano plots of the DEGs obtained from the GEO and TCGA databases are shown in Figs. 1 and 2. Heatmaps were created to visualize the expression values of DEGs in the different samples, while volcano plots were plotted to present the distribution of each gene based on the criteria of an adjusted $\mathrm{P}<0.01$ and a llog fold-changel of $>2.0$. Via comprehensive bioinformatics analysis of these DEGs, 126 DEGs that existed in both the GEO and TCGA databases were identified, including 70 upregulated and 56 downregulated genes (Table I).

Functional enrichment analyses of DEGS. The present study used DAVID and R software to perform functional and pathway enrichment analyses for identifying the biological classification of DEGs. The following conclusions were drawn: i) The DEGs were enriched in 83 GO terms; ii) the biological processes (BP) of DEGs were primarily enriched in 'negative regulation of growth', 'cell division', 'cell proliferation', 'cell migration' and 'cell cycle'; iii) molecular function (MF) was mainly enriched in 'oxygen binding', 'monooxygenase activity' and 'protein binding'; and iv) the 'midbody', 'cytosol' and 'nucleus' were primarily enriched in the cell components (CC) function (Table SI). The top ten GO terms are presented in (Fig. 3A). The results of the KEGG pathway enrichment analysis indicated that DEGs were primarily enriched in 18 pathways, with the top six being 'p53 signaling pathway' (hsa04115), 'cell cycle' (hsa04110), 'cellular senescence' (hsa04218), '5' AMP-activated protein kinase (AMPK) signaling pathway' (hsa04152), 'peroxisome proliferator-activated receptors (PPARs) signaling pathway' (hsa03320) and 'chemical carcinogenesis' (hsa05204) (Fig. 3B).

Construction of PPI network and analysis of modules. The PPI network of hub genes, which was composed of 102 nodes and 1,023 edges, was constructed using the STRING website and visualized by Cytoscape (Fig. 4A). The most essential module was obtained using MCODE, a Cytoscape plugin, and is presented in (Fig. 4B). DAVID was used to identify GO items of modules that were significant $(\mathrm{P}<0.05)$. Moreover, it was demonstrated that 'cell division', 'cell cycle', 'cell division', 'DNA repair' and 'regulation of cell cycle' were the five most significantly enriched BP of the module (data not shown).

Selection and analysis of hub genes. The top eight genes that had $>44$ nodes in the PPI network were selected as hub genes. The names, coded proteins and functions of these hub genes are presented in Table II. A Kaplan-Meier curve for these eight hub genes was constructed in cBioPortal, and it was demonstrated that patients with alterations in cyclin B1 (CCNB1), cell-division cycle protein 20 (CDC20), BUB1 mitotic checkpoint serine/threonine kinase $\beta$ (BUB1B) and ubiquitin-conjugating enzyme E2C (UBE2C) exhibited worse disease-free survival (Fig. 5A) and overall survival rate (Fig. 5B). Subsequently, the results of the expression of these four genes were validated in the Oncomine database, and it was indicated that BUB1B and UBE2C were significantly upregulated in $\mathrm{HCC}$ in different datasets (Fig. 6). By analyzing the Wurmbach liver dataset, it was speculated that high expression of these two genes is associated with tumor grade, hepatitis virus infection status, satellites and vascular invasion (Fig. 7). 
Table I. DEGs $(n=151)$ in The Cancer Genome Atlas and Gene Expression Omnibus databases.

DEGs Genes

Downregulated

Upregulated
MT1M, HAMP, CNDP1, SLC22A1, APOF, CLEC4M, FCN3, CLEC1B, CRHBP, KCNN2, OIT3, CYP1A2, CLEC4G, FOS, C9, MT1F, GYS2, CYP2C19, FOSB, TTC36, MT1H, HAO2, GBA3, SLCO1B3, CYP26A1, MT1E, NAT2, CYP2B6, PCK1, BCO2, MT1X, LPA, MARCO, CYP4A11, NPY1R, MT1G, SLC25A47, GHR LYVE1, ASPG PLAC8, CXCL14, IGFALS, CFP, TSLP, FCN2, IL1RAP, FBP1, DIRAS3, RDH16, PZP, MT2A, RND3, AADAT, CYP39A1, CETP

KIF15, SHCBP1, MMP12, ESM1, STK39, UHRF1, CENPE, CEP55, COX7B2, TPX2, S100P, GMNN, ZWINT, CENPL, TRIM71, EZH2, BEX2, MDK, E2F8, TRIP13, CCNA2, CRNDE, NEK2, CD24, CDK1, KIF4A, DEPDC1B, PEG10, ACSL4, FOXM1, MELK, CDC20, FLVCR1, ZIC2, OIP5, FAM83D, NQO1, NUSAP1, RBM24, ANLN, SULT1C2, ASPM, NCAPG, NDC80, UBE2T, UBE2C, RAD51AP1, TOP2A, PRC1, DLGAP5, KIF20A, DTL, HMMR, TTK, NUF2, ROBO1, CENPW, BUB1B, GPC3, GINS1, PBK, CCNB1, CTHRC1, COL15A1, CDKN3, RACGAP1, CAP2, RRM2, AKR1B10, SPINK1

DEGs, differentially expressed genes.
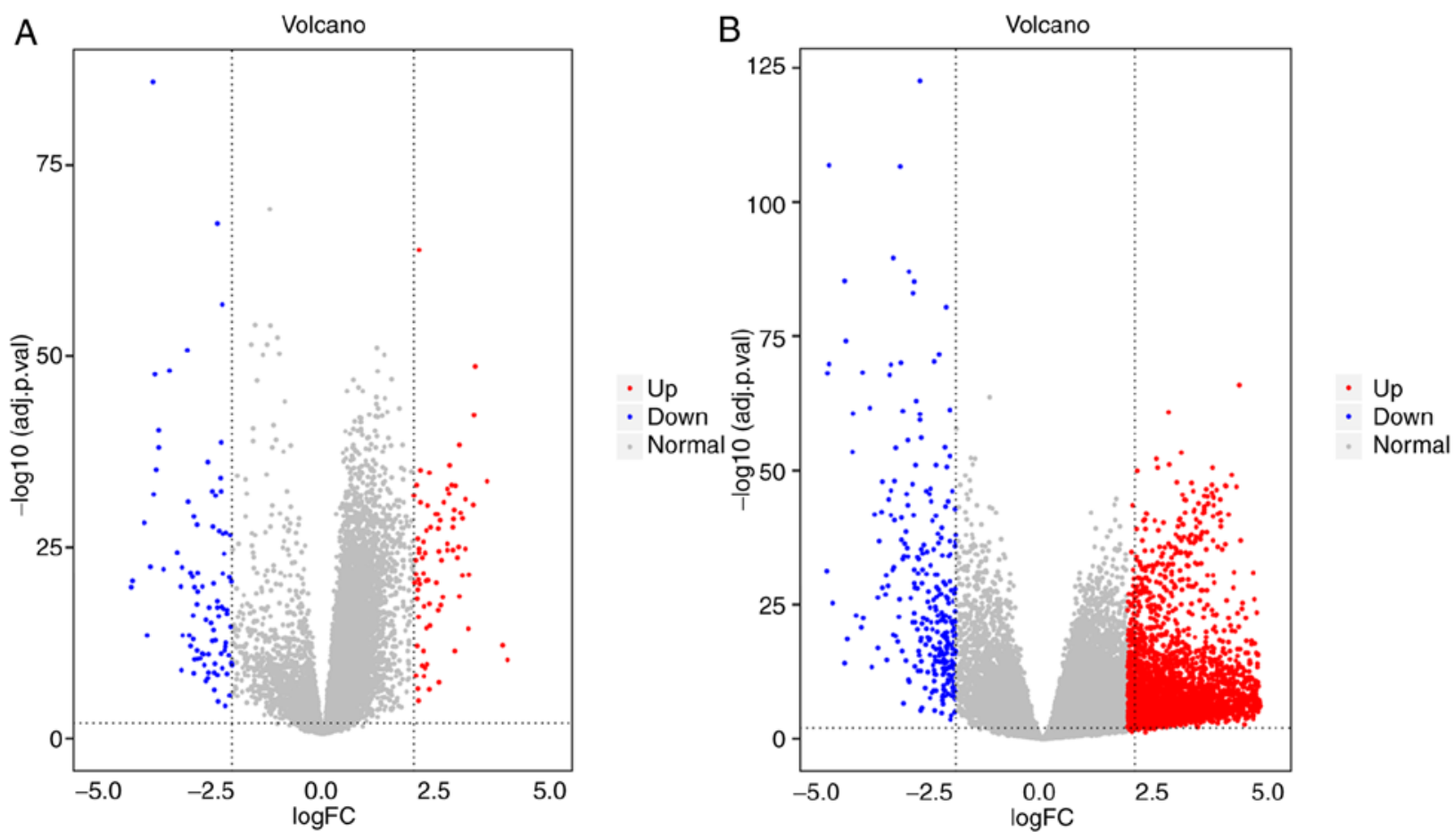

Figure 2. Volcano plots of differentially expressed genes used to distinguish HCC from healthy tissue. Red dots represent genes that were significantly upregulated in HCC; blue dots represent genes that were significantly downregulated in HCC; grey dots represent genes that were not differentially expressed. (A) Gene Expression Omnibus datasets. (B) The Cancer Genome Atlas datasets. HCC, hepatocellular carcinoma.

After deleting the incomplete sample information of the clinical data, a univariate analysis was performed. The results suggested that high expression levels of BUB1B and UBE2C, tumor stage, $\mathrm{T}$ classification and metastasis predicted poorer survival, and multivariate Cox analyses demonstrated that BUB1B and UBE2C were independent prognostic factors for HCC (Tables III and IV). Collectively, the results suggested that the alteration of BUB1B and UBE2C may be a potential target for the diagnosis and treatment of HCC.

GSEA. The GSEA results indicated that the high-expression phenotypes of BUB1B and UBE2C were significantly associated with tumor-associated pathways ( $\mathrm{P}<0.05$; FDR $<0.25$; Fig. 8), including 'p53 signaling pathway', 'cell cycle', 'WNT signaling pathway', 'T-cell receptor signaling pathway', 'vascular endothelial growth factor (VEGF) signaling pathway' and other pathways associated with malignant tumors.

\section{Discussion}

Recently, with the improvement of genome sequencing, biochips and high-throughput sequencing technology, an increasing number of studies have used bioinformatics methods for chip datasets analysis, which provides a novel and 

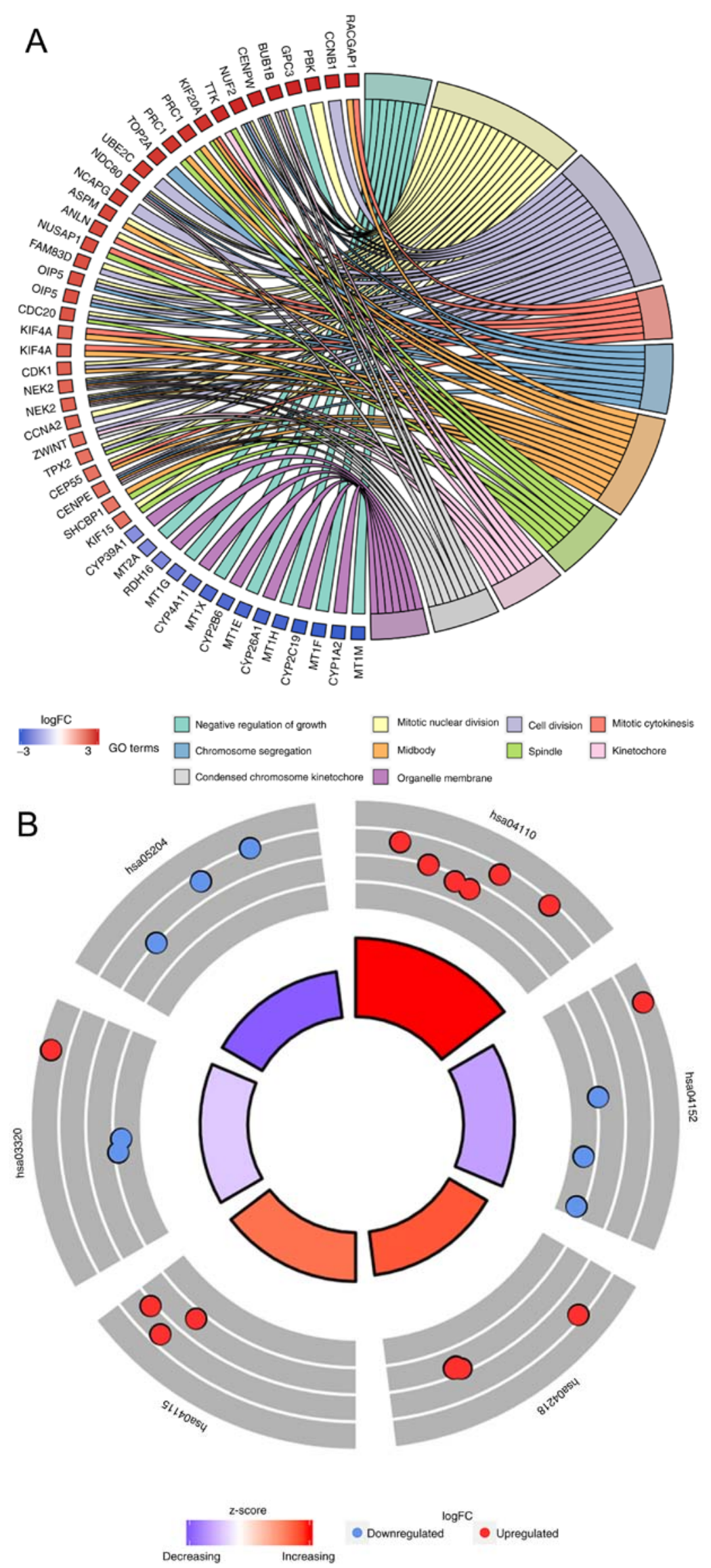

Figure 3. Functional enrichment analyses of DEGs. (A) GOChord plot of GO analyses, with the top ten GO terms. The left side of the GOChord diagram represents $\log \mathrm{FC}$, and the right side represents different GO terms. The connecting bands indicate the corresponding pathways for each gene. (B) GOCircle plot of KEGG pathway analyses, including the top six KEGG pathways. The height of the inner ring indicates the significance of the term (-log10 P-value), and the color represents the z-score. The outer ring indicates the logFC of the genes in each GO term. DEGs, differentially expressed genes; GO, Gene Ontology; KEGG, Kyoto Encyclopedia of Genes and genomes. 
Table II. Function of eight hub genes.

\begin{tabular}{|c|c|c|c|c|}
\hline No. & Gene symbol & Protein & Function & (Refs) \\
\hline 1 & CCNB1 & $\begin{array}{l}\text { G2/mitotic-specific } \\
\text { cyclin-B1 }\end{array}$ & $\begin{array}{l}\text { Control of the cell cycle at the } \mathrm{G}_{2} / \mathrm{M} \\
\text { (mitosis) transition }\end{array}$ & $\begin{array}{l}\text { Brown et al, } 2007 \text { (58); } \\
\text { Petri et al, } 2007 \text { (56). }\end{array}$ \\
\hline 2 & CDK1 & $\begin{array}{l}\text { Cyclin-dependent } \\
\text { kinase } 1\end{array}$ & $\begin{array}{l}\text { Regulation of cell cycle progression, } \\
\text { apoptosis and carcinogenesis of } \\
\text { tumor cells }\end{array}$ & $\begin{array}{l}\text { Qiao et al, } 2006 \text { (59); } \\
\text { Wang et al, } 2011 \text { (55). }\end{array}$ \\
\hline 3 & BUB1B & $\begin{array}{l}\text { BUB1 mitotic } \\
\text { checkpoint serine/ } \\
\text { threonine kinase } \beta\end{array}$ & $\begin{array}{l}\text { Essential component of the mitotic } \\
\text { checkpoint; mutated in colorectal } \\
\text { cancer and other tumors }\end{array}$ & $\begin{array}{l}\text { Shin et al, } 2003(38) \text {; } \\
\text { Yamamoto et al, 2007 (40); } \\
\text { Liu et al, } 2009(41) ; \\
\text { Fu et al, } 2016(42) \text {. }\end{array}$ \\
\hline 4 & $\mathrm{CDC} 20$ & Cell division cycle 20 & $\begin{array}{l}\text { Regulatory protein that participates } \\
\text { in cell cycle processes }\end{array}$ & $\begin{array}{l}\text { Zhang et al, } 2019 \text { (36); } \\
\text { Cheng et al, } 2019 \text { (37). }\end{array}$ \\
\hline 5 & CCNA2 & Cyclin-A2 & $\begin{array}{l}\text { Controls the } \mathrm{G}_{1} / \mathrm{S} \text { and the } \mathrm{G}_{2} / \mathrm{M} \\
\text { transition phases of the cell cycle }\end{array}$ & Pagano et al, 1992 (60). \\
\hline 6 & UBE2C & $\begin{array}{l}\text { Ubiquitin-conjugating } \\
\text { enzyme E2 C }\end{array}$ & $\begin{array}{l}\text { Involved in ubiquitination during } \\
\text { protein modification }\end{array}$ & $\begin{array}{l}\text { Williamson et al, } 2009 \text { (45); } \\
\text { David et al, } 2010 \text { (61). }\end{array}$ \\
\hline 7 & ZWINT & ZW10 interactor & $\begin{array}{l}\text { Member of the MIS } 12 \text { complex; } \\
\text { participates in biological processes } \\
\text { such as cell cycle and cell division }\end{array}$ & Lin et al, 2006 (50). \\
\hline 8 & NUSAP1 & $\begin{array}{l}\text { Nucleolar and spindle- } \\
\text { associated protein } 1\end{array}$ & $\begin{array}{l}\text { High expression may be associated } \\
\text { with prostate, colon and liver cancer }\end{array}$ & $\begin{array}{l}\text { Gordon et al, } 2017 \text { (53); Liu et al, } \\
2018 \text { (54); Zhou et al, } 2018 \text { (34) }\end{array}$ \\
\hline
\end{tabular}

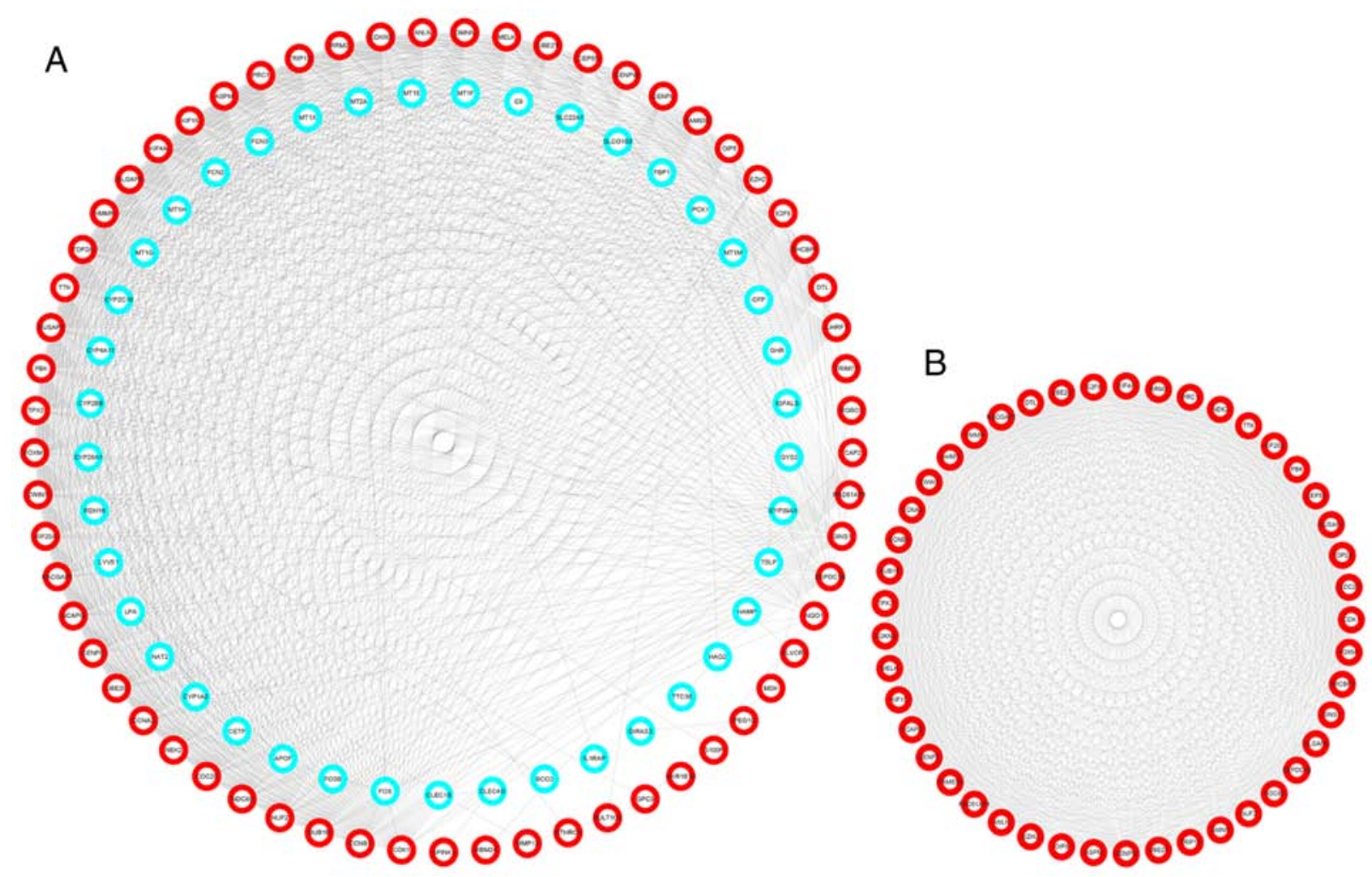

Figure 4. PPI network. (A) PPI network of DEGs with red marking upregulated and blue marking downregulated genes. (B) The most significant module in the PPI network consisted of 45 nodes and 922 edges. PPI, protein-protein interaction; DEGs, differentially expressed genes.

effective way to identify promising markers for HCC diagnosis and treatment $(13-15,34,35)$. In contrast to previous studies, in the present study three datasets (GSE112790, GSE84402 and
GSE74656) were downloaded from GEO and RNA-seq data from TCGA, and were combined to determine the DEGs of tumor and healthy tissues via comprehensive bioinformatics 

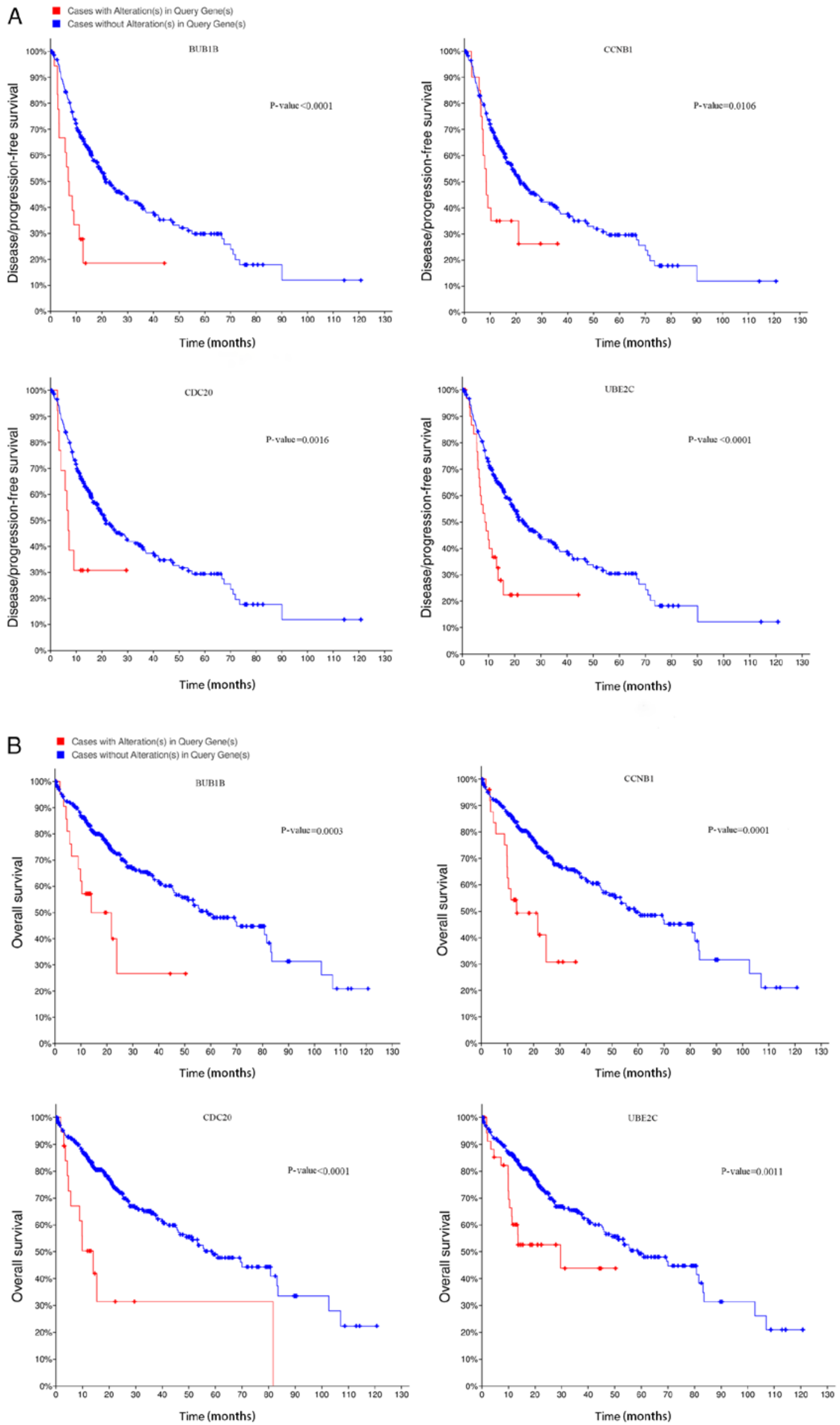

Figure 5. Selection and analysis of hub genes. Analyses of (A) disease-free and (B) overall survival rate of hub genes. CDC20, cell division cycle 20; UBE2C, ubiquitin-conjugating enzyme E2 C; BUB1B, BUB1 mitotic checkpoint serine/threonine kinase $\beta$; CCNB1, cyclin-B1. 


\begin{tabular}{|c|c|c|c|c|c|c|}
\hline Median rank & P-Value & Gene & & & & \\
\hline \multirow[t]{2}{*}{145.0} & $2.26 \times 10^{-10}$ & BUB1B & & & & \\
\hline & & & 1 & 2 & 3 & 4 \\
\hline Median rank & P-Value & Gene & & & & \\
\hline \multirow[t]{2}{*}{61.5} & $1.78 \times 10^{-11}$ & UBE2C & & & & \\
\hline & & & 1 & 2 & 3 & 4 \\
\hline
\end{tabular}

Legend

1. Hepatocellular Carcinoma vs. Normal Chen Liver, Mol Biol Cell, 2002

2. Hepatocellular Carcinoma vs. Normal Roessler Liver, Cancer Res, 2010

\section{Hepatocellular Carcinoma vs. Normal Roessler Liver 2, Cancer Res, 2010}

4. Hepatocellular Carcinoma vs. Normal Wurmbach Liver, Hepatology, 2007

\section{$\square \square^{15} \square^{10} \square_{\%}^{25} \square^{25} \square^{10} \square^{5} \square^{1} \square$ Not measured}

Rank for a gene is the median rank for that gene across each of the analyses.

$\mathrm{P}$-Value for a gene is its $\mathrm{P}$-Value for the median-ranked analysis.

Figure 6. Comparison of the expression difference of two core genes between tumors and healthy tissues. UBE2C, ubiquitin-conjugating enzyme E2C; BUB1B, BUB1 mitotic checkpoint serine/threonine kinase $\beta$.

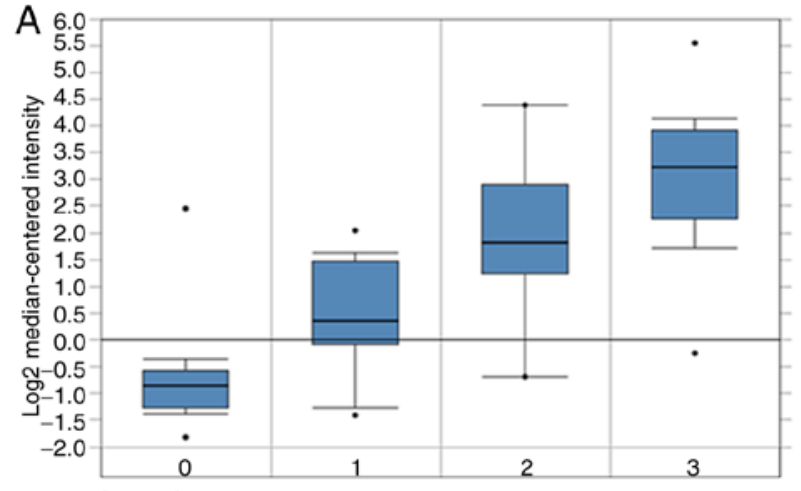

Legend

0. No value (42)
1. Grade $1(12)$
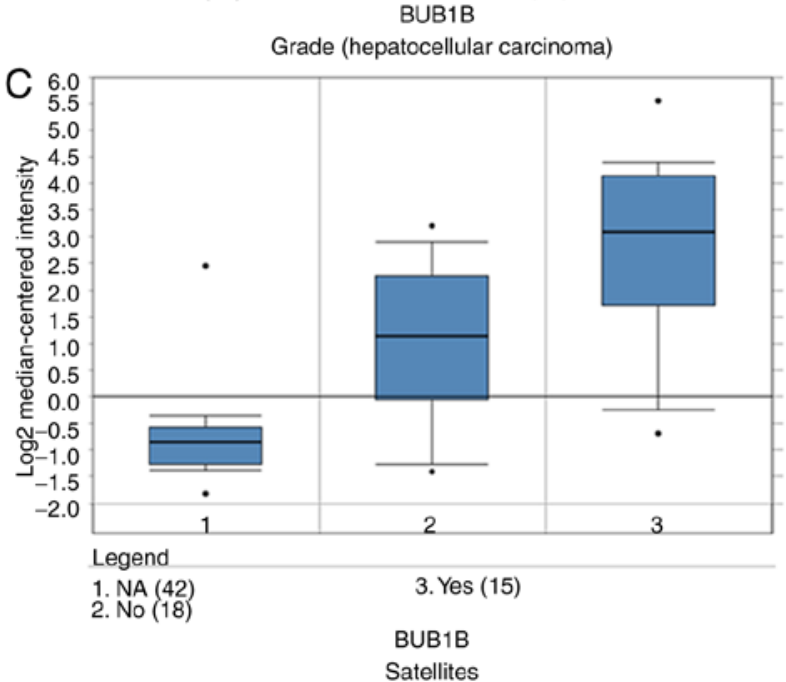

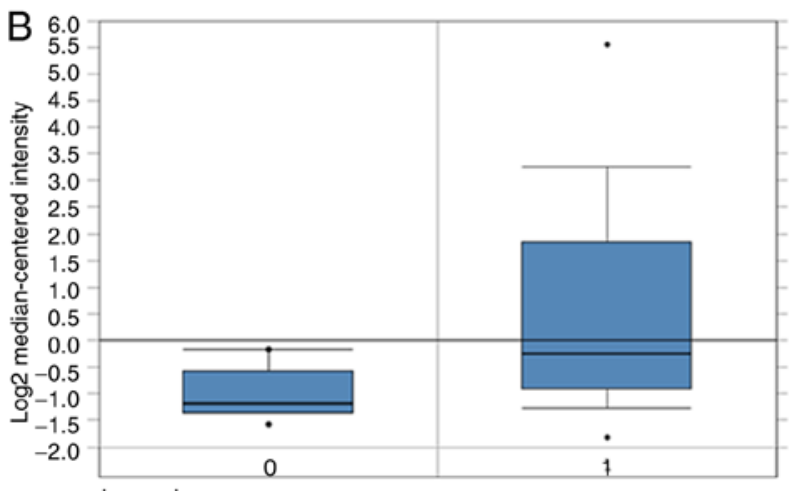

Legend

1. Ho value $(10)$

BUB1B

Hepatitis virus infection status

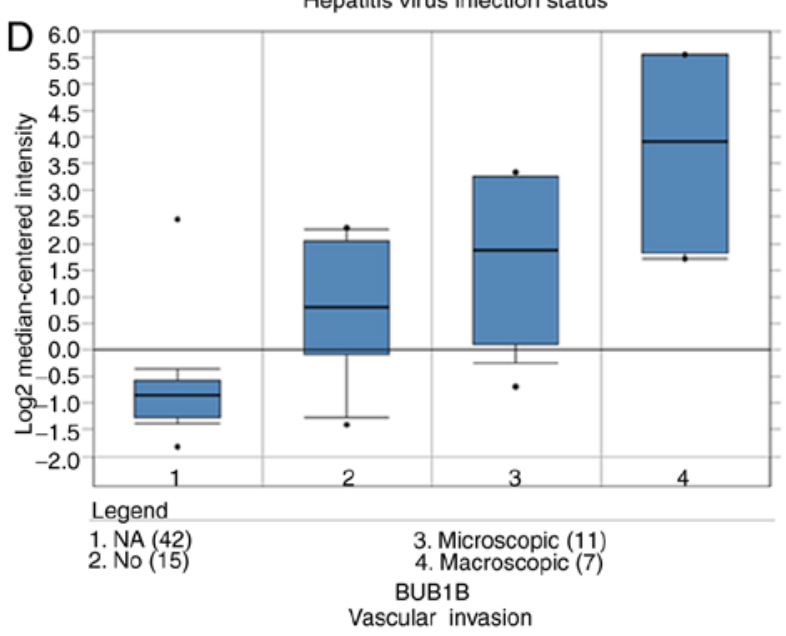

Figure 7. Association between BUB1B mRNA expression and (A) tumor grade, (B) hepatitis virus infection status, (C) satellites and (D) vascular invasion. 

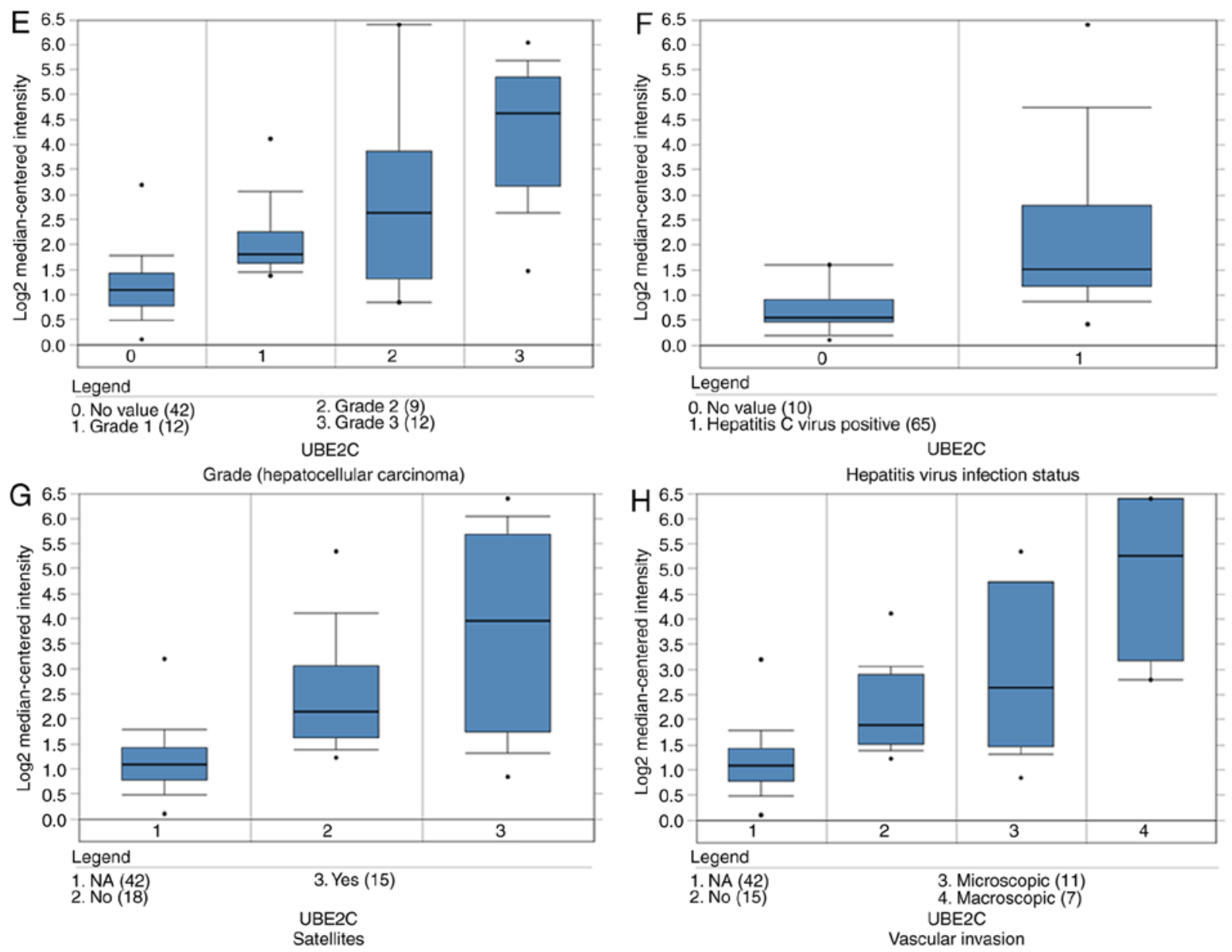

Figure 7. Continued. Association between UBE2C mRNA expression and (E) tumor grade, $(\mathrm{F})$ hepatitis virus infection status, $(\mathrm{G})$ satellites and $(\mathrm{H})$ vascular invasion. UBE2C, ubiquitin-conjugating enzyme E2C; BUB1B, BUB1 mitotic checkpoint serine/threonine kinase $\beta$.
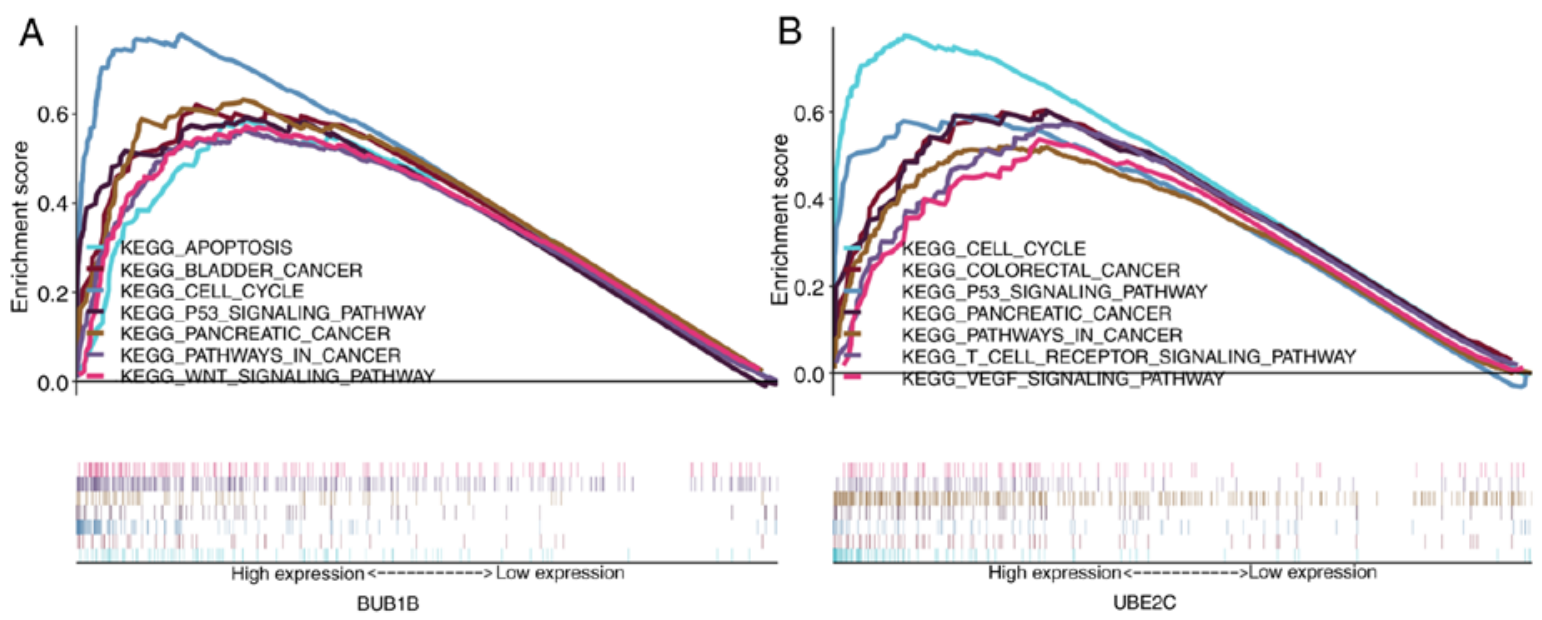

Figure 8. Enrichment plots from gene set enrichment analysis. (A) Signaling pathways of BUB1B. (B) Signaling pathways of UBE2C. UBE2C, ubiquitinconjugating enzyme E2 C; BUB1B, BUB1 mitotic checkpoint serine/threonine kinase $\beta$; KEGG, Kyoto Encyclopedia of Genes and Genomes; WNT, wingless-related integration; VEGF, vascular endothelial growth factor.

analysis methods. A total of 126 hub genes were selected, including 56 downregulated and 70 upregulated genes. Subsequently, the present study performed GO and KEGG pathway analyses for these DEGs. It was found that BPs were mainly involved in 'negative regulation of growth', 'cell division', 'cell proliferation', 'cell migration' and 'cell cycle,' while
CC primarily contained the 'midbody', 'cytosol' and 'nucleus'. Moreover, MF of DEGs were primarily enriched in 'oxygen binding', 'monooxygenase activity' and 'protein binding'. In addition, KEGG were mainly enriched in 'p53 signaling pathway', 'cell cycle', 'cellular senescence' and 'AMPK signaling pathway'. 
Table III. Univariate and multivariate analyses of the correlation of BUB1B expression with overall survival.

\begin{tabular}{|c|c|c|c|c|c|c|}
\hline \multirow[b]{2}{*}{ Parameter } & \multicolumn{3}{|c|}{ Univariate analysis } & \multicolumn{3}{|c|}{ Multivariate analysis } \\
\hline & HR & $95 \% \mathrm{CI}$ & P-value & HR & $95 \% \mathrm{CI}$ & P-value \\
\hline Age & 1.005 & $0.987-1.023$ & 0.5912 & 1.013 & $0.993-1.033$ & 0.2144 \\
\hline Sex & 0.780 & $0.487-1.249$ & 0.3012 & 1.105 & $0.654-1.869$ & 0.7088 \\
\hline Histological grade & 1.017 & $0.746-1.387$ & 0.9143 & 1.003 & $0.715-1.406$ & 0.9871 \\
\hline TNM stage & 1.865 & $1.456-2.388$ & $<0.0001$ & 0.961 & $0.361-2.556$ & 0.9366 \\
\hline T classification & 1.804 & $1.434-2.270$ & $<0.0001$ & 1.690 & $0.702-4.066$ & 0.2414 \\
\hline M classification & 3.850 & $1.207-12.281$ & 0.0228 & 2.313 & $0.580-9.220$ & 0.2346 \\
\hline $\mathrm{N}$ classification & 2.022 & $0.494-8.276$ & 0.3276 & 1.690 & $0.266-10.728$ & 0.5779 \\
\hline BUB1B & 1.329 & $1.157-1.527$ & $<0.0001$ & 1.295 & $1.111-1.508$ & $<0.0001$ \\
\hline
\end{tabular}

HR, hazard ratio; CI, confidence interval; TNM, tumor-node-metastasis; BUB1B, BUB1 mitotic checkpoint serine/threonine kinase $\beta$.

Table IV. Univariate and multivariate analyses of the correlation of UBE2C expression with overall survival.

\begin{tabular}{|c|c|c|c|c|c|c|}
\hline \multirow[b]{2}{*}{ Parameter } & \multicolumn{3}{|c|}{ Univariate analysis } & \multicolumn{3}{|c|}{ Multivariate analysis } \\
\hline & HR & $95 \% \mathrm{CI}$ & P-value & HR & $95 \% \mathrm{CI}$ & P-value \\
\hline Age & 1.005 & $0.987-1.023$ & 0.5912 & 1.014 & $0.994-1.035$ & 0.1755 \\
\hline Sex & 0.780 & $0.487-1.249$ & 0.3012 & 1.123 & $0.666-1.894$ & 0.6628 \\
\hline Histological grade & 1.017 & $0.746-1.387$ & 0.9143 & 0.983 & $0.703-1.375$ & 0.9189 \\
\hline TNM stage & 1.865 & $1.456-2.388$ & $<0.0001$ & 0.941 & $0.360-2.462$ & 0.9011 \\
\hline $\mathrm{T}$ classification & 1.804 & $1.434-2.270$ & $<0.0001$ & 1.728 & $0.729-4.093$ & 0.2138 \\
\hline M classification & 3.850 & $1.207-12.281$ & 0.0227 & 1.970 & $0.507-7.656$ & 0.3277 \\
\hline $\mathrm{N}$ classification & 2.022 & $0.494-8.276$ & 0.3275 & 1.904 & $0.314-11.554$ & 0.4840 \\
\hline UBE2C & 1.374 & $1.194-1.582$ & $<0.0001$ & 1.332 & $1.145-1.550$ & $<0.0001$ \\
\hline
\end{tabular}

HR, hazard ratio; CI, confidence interval; TNM, tumor-node-metastasis; UBE2C, ubiquitin-conjugating enzyme E2C.

Among the 126 DEGs that were identified, a total of eight hub genes were screened, including CCNB1, CDC20, cyclin-dependent kinase 1 (CDK1), BUB1B, cyclin A2 (CCNA2), nucleolar and spindle-associated protein 1 (NUSAP1), UBE2C and ZW10 interactor (ZWINT). A survival analysis was performed on these hub genes, and it was demonstrated that alterations in CCNB1, CDC20, BUB1B and UBE2C indicated poor outcomes, while alterations in CDK1, CCNA2, NUSAP1 and ZWINT did not result in meaningful differences (data not shown). In addition, the present study compared four different groups of experimental results in Oncomine, and analysis of tumoral and healthy tissue identified that BUB1B and UBE2C were significantly upregulated and highly associated with tumor grade, hepatitis virus infection status, satellites and vascular invasion, thus suggesting that these selected genes may play a critical role in the initiation of HCC. Furthermore, univariate and multivariate Cox analysis results suggested that BUB1B and UBE2C were independent prognostic factors for HCC. In addition, GSEA analysis identified the pathways via which these two genes may function, including t 'p53 signaling pathway', 'cell cycle', 'WNT signaling pathway', 'T-cell receptor', 'VEGF signaling pathway' and other pathways associated with malignant tumors.
In the present study, CDC20 was primarily involved in 'mitotic nuclear division' and 'cell division' of BPs and the 'spindle' and 'cytoplasm' (data not shown) of the cell. Zhang et al (36), reported that high expression of CDC20 in prostate cancer often indicates a poor prognosis. Moreover, a previous study revealed that CDC20 is associated with tumor metastasis (37); thus, future research should focus on CDC20 target inhibitors to develop new drugs to inhibit tumor metastasis.

As a significant checkpoint of cell mitosis, BUB1B is involved in the normal process of cell mitosis (38), and upregulation of BUB1B is observed in various human malignancies, which are associated with the development and progression of the tumor, as well as aggressive biological features (39-42). However, low expression of BUB1B in colon adenocarcinoma (43) and lung tumor (44) causes metastasis and poorer survival.

$\mathrm{UBE} 2 \mathrm{C}$ is a protein in the UBE2 family, which is involved in ubiquitination during protein modification, and degrades anaphase promoting complex/cyclosome substrates via proteasomes and promotes mitotic exit (45). Zhang et al (46), revealed that UBE2C is highly expressed in gastric cancer, which could lead to the occurrence and development of 
malignant tumors, and this upregulation is significantly associated with lymph node metastasis and tumor stage. In addition, high expression of UBE2C is also closely associated with breast cancer, colon cancer and other malignant tumors (47-49).

ZWINT is a member of the MIS12 kinetochore complex component, which is necessary for spindle checkpoint activity. It also participates in biological processes such as cell cycle and cell division (50), and may be a promising target for tumor therapy. Previous studies have reported that CCNA2 expression is elevated in human breast cancer and pancreatic ductal adenocarcinoma $(35,51)$. Moreover, NUSAP1 may be involved in the regulation of chromosome alignment (52), and several studies have revealed that its expression in high levels is associated with prostate, colon and liver cancer $(34,53,54)$. In addition, CDK1 may be an underlying therapeutic target for the treatment of cancer, as it is a principal regulatory agent for the cell cycle, and functions by controlling the centrosome cycle and the initiation of mitosis (55). The protein CCNB1 plays a pivotal role in tumor aggressiveness by modulating the cell cycle at the $\mathrm{G}_{2} / \mathrm{M}$ (mitosis) transition (56). Zhuang et al (57) also indicated that upregulation of CCNB1 may predict poor prognosis in patients with HCC.

In conclusion, the present study performed preliminary examinations to identify the mechanism underlying the initiation of cancer formation, as well as the development and progression of HCC. Comprehensive bioinformatics analyses were performed in order to identify 126 DEGs and eight hub genes. Furthermore, the results demonstrated that BUB1B and UBE2C may be potential targets for the diagnosis and treatment of HCC. However, the main limitation of the present study is the lack of quantitative PCR analysis to verify the expression levels of BUB1B and UBE2C. Collectively, the present study provides a new direction for further studies on HCC. The DEGs identified in HCC tissues may be involved in carcinogenesis and progression. Particularly, BUB1B and $\mathrm{UBE} 2 \mathrm{C}$, may serve as potential candidate biomarkers and therapeutic targets for HCC. Future studies should focus on the verification of the present findings in clinical practice and on identifying the molecular mechanisms involved in HCC.

\section{Acknowledgements}

Not applicable.

\section{Funding}

This study was funded by the National Natural Science Foundation of China (grant no. 81872036) and The First Hospital of Lanzhou University Fund 2017 (grant no. ldyyyn2017-04).

\section{Availability of data and materials}

The datasets analyzed during the present study are available in the GEO (https:/www.ncbi.nlm.nih.gov/geo/) and TCGA repositories (https://cancergenome.nih.gov/).

\section{Authors' contributions}

NM and JC designed the study and wrote the initial draft of the manuscript. JZ, WF, CH and LG contributed to the analysis and interpretation of data. PY and $\mathrm{BB}$ helped to design the study and acquire data, YL, WM and XL participated in interpreting the results and revised the writing of manuscript. All authors have reviewed and approved the final manuscript.

\section{Ethics approval and consent to participate}

Not applicable.

\section{Patient consent for publication}

Not applicable.

\section{Competing interests}

The authors declare that they have no competing interests.

\section{References}

1. McGlynn KA, Petrick JL and El-Serag HB: Epidemiology of hepatocellular carcinoma. Hepatology Apr 22, 2020 (Epub ahead of print).

2. Bray F, Ferlay J, Soerjomataram I, Siegel RL, Torre LA and Jemal A: Global cancer statistics 2018: GLOBOCAN estimates of incidence and mortality worldwide for 36 cancers in 185 countries. CA Cancer J Clin 68: 394-424, 2018.

3. Maluccio M and Covey A: Recent progress in understanding, diagnosing, and treating hepatocellular carcinoma. CA Cancer J Clin 62: 394-399, 2012.

4. Forner A, Reig M and Bruix J: Hepatocellular carcinoma. Lancet 391: 1301-1314, 2018.

5. Parkin DM: The global health burden of infection-associated cancers in the year 2002. Int J Cancer 118: 3030-3044, 2006.

6. Rinella ME: Nonalcoholic fatty liver disease: A systematic review. JAMA 313: 2263-2273, 2015.

7. Mirizzi A, Franco I, Leone CM, Bonfiglio C, Cozzolongo R, Notarnicola M, Giannuzzi V, Tutino V, De Nunzio V, Bruno I, et al: Effects of some food components on non-alcoholic fatty liver disease severity: Results from a cross-sectional study. Nutrients 11: 2744, 2019.

8. Dimitroulis D, Damaskos C, Valsami S, Davakis S, Garmpis N, Spartalis E, Athanasiou A, Moris D, Sakellariou S, Kykalos S, et al: From diagnosis to treatment of hepatocellular carcinoma: An epidemic problem for both developed and developing world. World J Gastroentero 23: 5282-5294, 2017.

9. Fuks D, Dokmak S, Paradis V, Diouf M, Durand F and Belghiti J: Benefit of initial resection of hepatocellular carcinoma followed by transplantation in case of recurrence: An intention-to-treat analysis. Hepatology 55: 132-140, 2012.

10. Han HS, Shehta A, Ahn S, Yoon YS, Cho JY and Choi Y: Laparoscopic versus open liver resection for hepatocellular carcinoma: Case-matched study with propensity score matching. J Hepatol 63: 643-650, 2015.

11. Hartke J, Johnson M and Ghabril M: The diagnosis and treatment of hepatocellular carcinoma. Semin Diagn Pathol 34: 153-159, 2017.

12. Zhang P, Yang Y, Wen F, He X, Tang R, Du Z, Zhou J, Zhang J and Li Q: Cost-effectiveness of sorafenib as a first-line treatment for advanced hepatocellular carcinoma. Eur J Gastroenterol Hepatol 27: 853-859, 2015.

13. Li L, Lei Q, Zhang S, Kong L and Qin B: Screening and identification of key biomarkers in hepatocellular carcinoma: Evidence from bioinformatic analysis. Oncol Rep 38: 2607-2618, 2017.

14. Zhang R, Ye J, Huang $\mathrm{H}$ and Du X: Mining featured biomarkers associated with vascular invasion in $\mathrm{HCC}$ by bioinformatics analysis with TCGA RNA sequencing data. Biomed Pharmacother 118: 109274, 2019.

15. Zhang C, Peng L, Zhang Y, Liu Z, Li W, Chen S and Li G: The identification of key genes and pathways in hepatocellular carcinoma by bioinformatics analysis of high-throughput data. Med Oncol 34: 101, 2017.

16. Shimada S, Mogushi K, Akiyama Y, Furuyama T, Watanabe S, Ogura T, Ogawa K, Ono H, Mitsunori Y, Ban D, et al: Comprehensive molecular and immunological characterization of hepatocellular carcinoma. EBioMedicine 40: 457-470, 2019. 
17. Wang H, Huo X, Yang XR, He J, Cheng L, Wang N, Deng X, Jin $\mathrm{H}$, Wang $\mathrm{N}$, Wang C, et al: STAT3-mediated upregulation of IncRNA HOXD-AS1 as a ceRNA facilitates liver cancer metastasis by regulating SOX4. Mol Cancer 16: 136, 2017.

18. Ritchie ME, Phipson B, Wu D, Hu Y, Law CW, Shi W and Smyth GK: Limma powers differential expression analyses for RNA-sequencing and microarray studies. Nucleic Acids Res 43: e47, 2015.

19. Bolstad BM, Irizarry RA, Astrand M and Speed TP: A comparison of normalization methods for high density oligonucleotide array data based on variance and bias. Bioinformatics 19: 185-193, 2003

20. Leek JT, Johnson WE, Parker HS, Jaffe AE and Storey JD: The sva package for removing batch effects and other unwanted variation in high-throughput experiments. Bioinformatics 28 : 882-883, 2012

21. Robinson MD, McCarthy DJ and Smyth GK: EdgeR: A Bioconductor package for differential expression analysis of digital gene expression data. Bioinformatics 26: 139-140, 2010.

22. Huang da W, Sherman BT and Lempicki RA: Systematic and integrative analysis of large gene lists using DAVID bioinformatics resources. Nat Protoc 4: 44-57, 2009.

23. Walter W, Sánchez-Cabo F and Ricote M: GOplot: An R package for visually combining expression data with functional analysis. Bioinformatics 31: 2912-2914, 2015.

24. Szklarczyk D, Gable AL,Lyon D,Junge A, Wyder S,Huerta-Cepas J, Simonovic M, Doncheva NT, Morris JH, Bork P, et al: STRING v11: Protein-protein association networks with increased coverage, supporting functional discovery in genome-wide experimental datasets. Nucleic Acids Res 47: D607-D613, 2019.

25. Demchak B, Hull T, Reich M, Liefeld T, Smoot M, Ideker T and Mesirov JP: Cytoscape: The network visualization tool for GenomeSpace workflows. F1000Res 3: 151, 2014.

26. Bader GD and Hogue CW: An automated method for finding molecular complexes in large protein interaction networks. BMC Bioinformatics 4: 2, 2003.

27. Gao J, Aksoy BA, Dogrusoz U, Dresdner G, Gross B, Sumer SO, Sun Y, Jacobsen A, Sinha R, Larsson E, et al: Integrative analysis of complex cancer genomics and clinical profiles using the cBioPortal. Sci Signal 6: pl1, 2013.

28. Cerami E, Gao J, Dogrusoz U, Gross BE, Sumer SO, Aksoy BA, Jacobsen A, Byrne CJ, Heuer ML, Larsson E, et al: The cBio cancer genomics portal: An open platform for exploring multidimensional cancer genomics data. Cancer Discov 2: 401-404, 2012.

29. Li H, Han D, Hou Y, Chen H and Chen Z: Statistical inference methods for two crossing survival curves: A comparison of methods. PLoS One 10: e0116774, 2015.

30. Rhodes DR, Kalyana-Sundaram S, Mahavisno V, Varambally R, Yu J, Briggs BB, Barrette TR, Anstet MJ, Kincead-Beal C, Kulkarni P, et al: Oncomine 3.0: Genes, pathways, and networks in a collection of 18,000 cancer gene expression profiles. Neoplasia 9: 166-180, 2007.

31. Wurmbach E, Chen YB, Khitrov G, Zhang W, Roayaie S, Schwartz M, Fiel I, Thung S, Mazzaferro V, Bruix J, et al: Genome-wide molecular profiles of HCV-induced dysplasia and hepatocellular carcinoma. Hepatology 45: 938-947, 2007.

32. Subramanian A, Tamayo P, Mootha VK, Mukherjee S, Ebert BL, Gillette MA, Paulovich A, Pomeroy SL, Golub TR, Lander ES and Mesirov JP: Gene set enrichment analysis: A knowledge-based approach for interpreting genome-wide expression profiles. Proc Natl Acad Sci USA 102: 15545-15550, 2005.

33. Liberzon A, Birger C, Thorvaldsdóttir H, Ghandi M, Mesirov JP and Tamayo P: The Molecular Signatures Database (MSigDB) hallmark gene set collection. Cell Syst 1: 417-425, 2015

34. Zhou L, Du Y, Kong L, Zhang X and Chen Q: Identification of molecular target genes and key pathways in hepatocellular carcinoma by bioinformatics analysis. Onco Targets Ther 11: 1861-1869, 2018.

35. Dong S, Huang F, Zhang $\mathrm{H}$ and Chen Q: Overexpression of BUB1B, CCNA2, CDC20 and CDK1 in tumor tissues predicts poor survival in pancreatic ductal adenocarcinoma. Biosci Rep 39: BSR20182306, 2019.

36. Zhang Q, Huang H, Liu A, Li J, Liu C, Sun B, Chen L, Gao Y, $\mathrm{Xu} D$ and Su C: Cell division Cycle 20 (CDC20) drives prostate cancer progression via stabilization of $\beta$-catenin in cancer stem-like cells. EBioMedicine 42: 397-407, 2019.

37. Cheng S, Castillo V and Sliva D: CDC20 associated with cancer metastasis and novel mushroom-derived CDC20 inhibitors with antimetastatic activity. Int J Oncol 54: 2250-2256, 2019.

38. Shin HJ, Baek KH, Jeon AH, Park MT, Lee SJ, Kang CM, Lee HS, Yoo SH, Chung DH, Sung YC, et al: Dual roles of human BubR1, a mitotic checkpoint kinase, in the monitoring of chromosomal instability. Cancer Cell 4: 483-497, 2003.
39. Ando K, Kakeji Y, Kitao H, Iimori M, Zhao Y, Yoshida R, Oki E, Yoshinaga K, Matumoto T, Morita M, et al: High expression of BUBR1 is one of the factors for inducing DNA aneuploidy and progression in gastric cancer. Cancer Sci 101: 639-645, 2010.

40. Yamamoto Y, Matsuyama H, Chochi Y, Okuda M, Kawauchi S, Inoue R, Furuya T, Oga A, Naito K and Sasaki K: Overexpression of BUBR1 is associated with chromosomal instability in bladder cancer. Cancer Genet Cytogen 174: 42-47, 2007.

41. Liu AW, Cai J, Zhao XL, Xu AM, Fu HQ, Nian H and Zhang SH: The clinicopathological significance of BUBR1 overexpression in hepatocellular carcinoma. J Clin Pathol 62: 1003-1008, 2009.

42. Fu X, Chen G, Cai ZD, Wang C, Liu ZZ, Lin ZY, Wu YD, Liang YX, Han ZD, Liu JC and Zhong WD: Overexpression of BUB1B contributes to progression of prostate cancer and predicts poor outcome in patients with prostate cancer. Onco Targets Ther 9: 2211-2220, 2016.

43. Shichiri M, Yoshinaga K, Hisatomi H, Sugihara K and Hirata Y: Genetic and epigenetic inactivation of mitotic checkpoint genes hBUB1 and hBUBR1 and their relationship to survival. Cancer Res 62: 13-17, 2002.

44. Park HY, Jeon YK, Shin HJ, Kim IJ, Kang HC, Jeong SJ, Chung DH and Lee CW: Differential promoter methylation may be a key molecular mechanism in regulating BubR1 expression in cancer cells. Exp Mol Med 39: 195-204, 2007.

45. Williamson A, Wickliffe KE, Mellone BG, Song L, Karpen GH and Rape M: Identification of a physiological E2 module for the human anaphase-promoting complex. Proc Natl Acad Sci USA 106: 18213-18218, 2009

46. Zhang HQ,Zhao G, Ke B, Ma G,Liu GL, Liang H,Liu LR and Hao XS: Overexpression of UBE2C correlates with poor prognosis in gastric cancer patients. Eur Rev Med Pharmacol Sci 22: 1665-1671, 2018.

47. Mo CH, Gao L, Zhu XF, Wei KL, Zeng JJ, Chen G and Feng ZB: The clinicopathological significance of UBE2C in breast cancer: A study based on immunohistochemistry, microarray and RNA-sequencing data. Cancer Cell Int 17: 83, 2017.

48. Bavi P, Uddin S, Ahmed M, Jehan Z, Bu R, Abubaker J, Sultana M, Al-Sanea N, Abduljabbar A, Ashari LH, et al: Bortezomib stabilizes mitotic cyclins and prevents cell cycle progression via inhibition of UBE2C in colorectal carcinoma. Am J Pathol 178: 2109-2120, 2011.

49. Dastsooz H, Cereda M,Donna D and Oliviero S: A comprehensive bioinformatics analysis of UBE2C in cancers. Int J Mol Sci 20: 2228, 2019.

50. Lin YT, Chen Y, Wu G and Lee WH: Hec1 sequentially recruits Zwint-1 and ZW10 to kinetochores for faithful chromosome segregation and spindle checkpoint control. Oncogene 25: 6901-6914, 2006.

51. Gao T, Han Y, Yu L, Ao S, Li Z and Ji J: CCNA2 is a prognostic biomarker for ER+ breast cancer and tamoxifen resistance. PLoS One 9: e91771, 2014.

52. Li CY, Xue C, Yang Q, Low BC and Liou YC: NuSAP governs chromosome oscillation by facilitating the Kid-generated polar ejection force. Nat Commun 7: 10597, 2016.

53. Gordon CA, Gong X, Ganesh D and Brooks JD: NUSAP1 promotes invasion and metastasis of prostate cancer. Oncotarget 8: 29935-29950, 2017.

54. Liu Z, Guan C, Lu C, Liu Y, Ni R, Xiao M and Bian Z: High NUSAP1 expression predicts poor prognosis in colon cancer. Pathol Res Pract 214: 968-973, 2018.

55. Wang Q, Su L, Liu N, Zhang L, Xu W and Fang H: Cyclin Dependent Kinase 1 Inhibitors: A review of recent progress. Curr Med Chem 18: 2025-2043, 2011.

56. Petri ET, Errico A, Escobedo L, Hunt T and Basavappa R: The crystal structure of human cyclin B. Cell Cycle 6: 1342-1349, 2007.

57. Zhuang L, Yang Z and Meng Z: Upregulation of BUB1B, CCNB1, CDC7, CDC20, and MCM3 in tumor tissues predicted worse overall survival and disease-free survival in hepatocellular carcinoma patients. Biomed Res Int 2018: 7897346, 2018.

58. Brown NR, Lowe ED, Petri E, Skamnaki V, Antrobus R and Johnson LN: Cyclin B and Cyclin A confer different substrate recognition properties on CDK2. Cell Cycle 6: 1350-1359, 2007.

59. Qiao M, Shapiro P, Fosbrink M, Rus H, Kumar R and Passaniti A: Cell cycle-dependent phosphorylation of the RUNX2 transcription factor by cdc2 regulates endothelial cell proliferation. J Biol Chem 281: 7118-7128, 2006.

60. Pagano M, Pepperkok R, Verde F, Ansorge W and Draetta G: Cyclin $\mathrm{A}$ is required at two points in the human cell cycle. EMBO J 11: 961-971, 1992.

61. David Y, Ziv T, Admon A and Navon A: The E2 ubiquitinconjugating enzymes direct polyubiquitination to preferred lysines. J Biol Chem 285: 8595-8604, 2010.

This work is licensed under a Creative Commons Attribution-NonCommercial-NoDerivatives 4.0 International (CC BY-NC-ND 4.0) License. 